\title{
Efficient Synthesis of 1,3,5-Oxygenated Synthons from Dimethyl 3-Oxoglutarate: First Use of Borane-dimethyl Sulfide Complex as a Regioselective Reducing Agent of 3-Oxygenated Glutarate Derivatives
}

\author{
Valéria B. Riatto, ${ }^{a, b}$ Maria N. M. Carneiro, ${ }^{a}$ Venília B. Carvalho ${ }^{c}$ and \\ Mauricio M. Victor*,a,b \\ ${ }^{a}$ Departamento de Química Orgânica, Instituto de Química, Universidade Federal da Bahia, \\ 40170-115 Salvador-BA, Brazil \\ ${ }^{b}$ Instituto Nacional de Ciência e Tecnologia em Energia e Ambiente, Universidade Federal \\ da Bahia, 40170-115 Salvador-BA, Brazil \\ 'Instituto de Ciências da Saúde, Centro Universitário FIB, 41770-130 Salvador-BA, Brazil
}

\begin{abstract}
A redução seletiva do 3-oxoglutarato de dimetila foi realizada em vários níveis. A redução quimiosseletiva da carbonila cetônica com boridreto de sódio é descrita em alto rendimento, fornecendo o 3-hidroxiglutarato de dimetila. Quando o complexo borana-dimetil sulfeto (BMS) foi empregado como agente redutor, um diol ou um triol puderam ser obtidos, respectivamente, a partir do 3-hidróxi- ou do 3-oxoglutarato, permitindo a síntese de compostos 1,3,5-oxigenados prática e eficientemente.
\end{abstract}

The selective reduction of dimethyl 3-oxoglutarate was accomplished in different levels. A high yielding sodium borohydride reduction of the keto group is fully described leading to dimethyl 3-hydroxyglutarate. When borane-dimethyl sulfide (BMS) complex was used, a diol or a triol compound can be obtained by selective or total reduction of 3-hydroxy- or 3-oxoglutarate, respectively, allowing an efficient and practical route to 1,3,5-oxygenated compounds.

Keywords: dimethyl 3-oxoglutarate, BMS complex, selective reduction, 1,3,5-oxygenated synthons

\section{Introduction}

Selectivity is imperative in modern organic synthesis, especially when multifunctional molecules are involved. The reagents and conditions employed for a chemical transformation must not affect other functional groups in the molecule, leading only to the required transformation. Among these selective procedures, reductions play an important role. ${ }^{1}$ Those transformations are known by their chemocompatibility, possibility of partial reduction, and regio- and stereoselectivity altered or controlled by neighboring groups, besides asymmetric transformations.

In this context, the selective reduction of dimethyl 3-oxoglutarate (1) to prepare dimethyl 3-hydroxyglutarate (2), diol $\mathbf{3}$ and triol $\mathbf{4}$ derivatives is an important approach in organic synthesis since these structures are useful intermediates in the preparation of complex molecules. ${ }^{2} \mathrm{~A}$

*e-mail: mmvictor@ufba.br chemo-, regio-, or total reduction of dimethyl 3-oxoglutarate allow access to 1,3,5-oxygenated derivatives in different oxidation states (Figure 1), creating a family of useful synthons in fast and accessible manner. Due this, we decided to explore routes from same precursor 1 in order to prepare that family of synthons, investigating either $\mathrm{NaBH}_{4}$ and BMS complex as reducing agents.

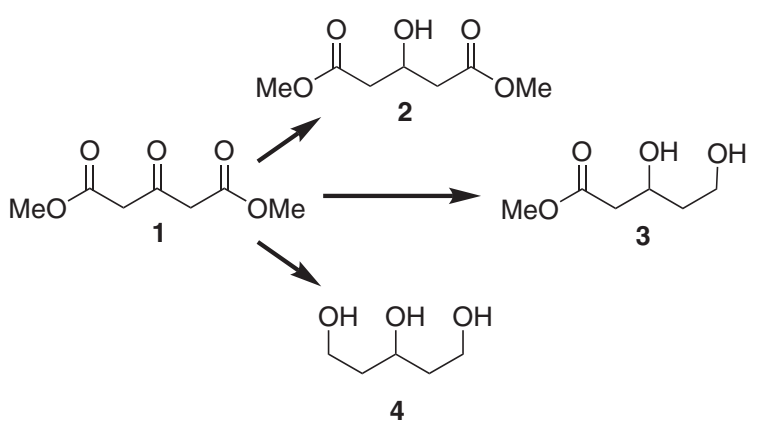

Figure 1. Synthesis of 1,3,5-oxygenated synthons from dimethyl 3-oxoglutarate. 


\section{Results and Discussion}

Our investigation began by exploring the chemoselective reduction of commercially available dimethyl 3-oxoglutarate (1) with $\mathrm{NaBH}_{4}$. Although also commercial, dimethyl 3-hydroxyglutarate (2), product of chemoselective reduction of $\mathbf{1}$, is more expensive, ${ }^{3}$ and its production from 3-oxoglutarate is described either via high pressure experiments, ${ }^{4}$ or in moderate yield procedures, ${ }^{5}$ or lacking experimental details. ${ }^{6}$ Our first attempt to the selective reduction of the keto group employed 1 equiv. of $\mathrm{NaBH}_{4}$ in $\mathrm{MeOH}$ as solvent, followed by treatment with acetic acid (standard conditions, Table 1, entry 1), but disappointingly low yields were obtained. Use of different acid treatment or higher temperatures just furnishes $\mathbf{2}$ in low yields (entries 2-4). Moderate results were obtained with nearly stoichiometric reducing agent quantities (entry 6). However, high yields were obtained with the addition of 0.3 equivalents of reducing agent to a solution of glutarate 1 in $\mathrm{MeOH}$, followed by acidification with solid citric acid.? 3-Hydroxy-diester $\mathbf{2}$ was isolated in $96 \%$ yield after column chromatography (entry 9).

Table 1. Chemoselective reduction of dimethyl 3-oxoglutarate (1)

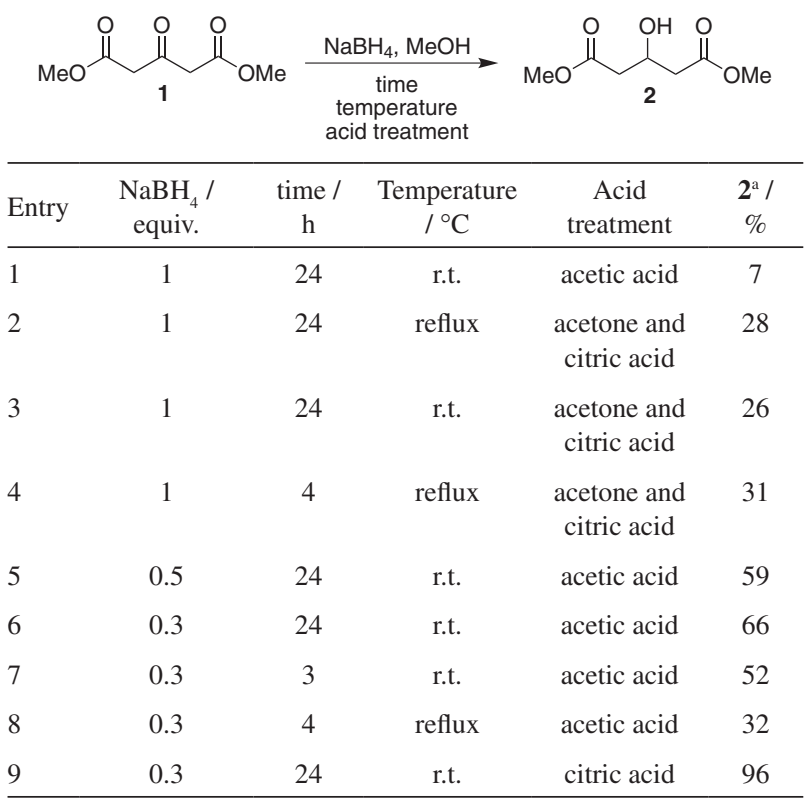

${ }^{a}$ Isolated yield of analytically pure products.

With a well-described procedure for keto-functional group reduction in hands, our next challenge was to achieve the regioselective reduction of the ester group. Inspiration came from dimethyl malate, where a neighboring $\alpha$-hydroxy group plays a crucial role directing the reduction reaction to only one ester site. ${ }^{8} \mathrm{~A}$ combination of borane-dimethyl sulfide (BMS) complex with catalytic sodium borohydride was very efficient in the regioselective reduction affording methyl 3,4-dihydroxy butanoate from dimethyl malate in $88 \%$ yield.

Chastrette and coworkers have proved to be possible to reach the complete reduction of malic esters when excess of reducing agent was employed. ${ }^{9}$ Indeed, the BMS complex with $\mathrm{NaBH}_{4}$ led to the reduction of an ester site with a $\beta$-oxygenated center. In this direction, we envisaged a possibility of access mono-reduction of ester functionality, controlling the amount of BMS added, as an expedient route to the preparation of synthon $\mathbf{3}$.

Diol 3 is actually accessible either by keto-reduction and debenzylation ${ }^{10}$ of ethyl 5-benzyloxy-3-oxopentanoate, ${ }^{11}$ or by organoselenium-mediated reduction of $\alpha, \beta$-epoxy- $\delta$-valerolactone. ${ }^{12}$ The first approach allowed the synthesis of $\mathbf{2}$ also in asymmetric fashion, but required the preparation of precursor and high pressure apparatus, while the second method of synthesis demanded a noncommercial reagent and a specific reducing agent.

Our attempt to obtain diol 3 was based on the possibility of carboxyl reduction directed by the $\beta$-oxygenated group. We planned to use the conditions described for the reduction of dimethyl malate to corresponding diol as substract. Oxo precursor 1 was also employed due to the possibility of in situ synthesis of 2 by $\mathrm{NaBH}_{4}$ reduction (Table 2, entries 1 and 2). Although 3 was selectively obtained, only moderate to low total yields were observed, along with triol 4 . In order to improve yield and selectivity, an increase in the amount of $\mathrm{NaBH}_{4}$ was evaluated. However, a decrease in yield and selectivity was observed (entries 3 and 4). Thus, we decided to investigate the BMS reduction ${ }^{13}$ without the addition of $\mathrm{NaBH}_{4}$. To our delight, better results (yields and selectivities) emerged (entries 5 and 7), specially when dimethyl 3-hydroxyglutarate (2) was employed. Finally, longer reaction time revealed to be advantageous for the preparation of diol 3 in $80 \%$ isolated yield (entry 8).

With a practical and efficient procedures to synthesize alcohol $\mathbf{2}$ and diol $\mathbf{3}$ established, we directed our attention to obtain an efficient methodology for the preparation of triol 4.

Syntheses of triol $\mathbf{4}$ were centered on the hydrogenation of dimethyl 3-oxoglutarate (1) with catalyst ${ }^{14}$ or reduction with $\mathrm{LiAlH}_{4}{ }^{15}$ However, only moderate yields were obtained. An alternative and high yield preparation of triol 4 is reported but employing an expensive reagent. ${ }^{16}$ Due to this, we decided to test modifications of our previously experimental conditions to access diol $\mathbf{3}$. Firstly, 3 equiv. of BMS complex were added to $\mathbf{1}$ and $\mathbf{2}$ at room temperature, furnishing moderate yield of triol $\mathbf{4}$ (Table 3, entries 1 and 2). An investigation of the effect of temperature was also carried out (entries 3 and 4), showing a positive result in total reduction of $\mathbf{1}$ (comparing with 
Table 2. Chemoselectivity in the preparation of diol 3

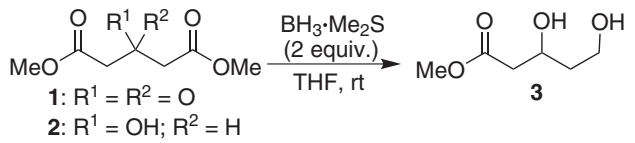

\begin{tabular}{lccccc}
\hline Entry & Substrate & $\mathrm{NaBH}_{4} /$ equiv. & time / & $\mathbf{3}^{\mathrm{a}} / \%$ & $\mathbf{4}^{\mathrm{a}} / \%$ \\
\hline 1 & $\mathbf{1}$ & 0.05 & 24 & 56 & 16 \\
2 & $\mathbf{2}$ & 0.05 & 24 & 17 & 9 \\
3 & $\mathbf{1}$ & 0.3 & 24 & 8 & 31 \\
4 & $\mathbf{2}$ & 0.3 & 24 & 12 & 25 \\
5 & $\mathbf{1}$ & - & 24 & 63 & 17 \\
6 & $\mathbf{1}$ & - & 48 & 26 & 51 \\
7 & $\mathbf{2}$ & - & 24 & 74 & 6 \\
8 & $\mathbf{2}$ & - & 48 & 80 & - \\
\hline
\end{tabular}

${ }^{a}$ Isolated yield of analytically pure products.

Table 2, entries 5 and 7). Whereas both $\mathbf{1}$ and $\mathbf{2}$ provided similar results, the use of dimethyl 3-oxoglutarate (1) avoided previous reduction, allowing direct synthesis of fully reduced compound. Longer reaction time (entry 5) and increased amount of BMS (entry 6) were evaluated only with 1. Finally, combining the positive effects of higher reaction temperature and larger amount of BMS fortunately led to triol $\mathbf{4}$ in excellent yield (98\% isolated yield).

Table 3. Chemoselectivity in the preparation of triol 4

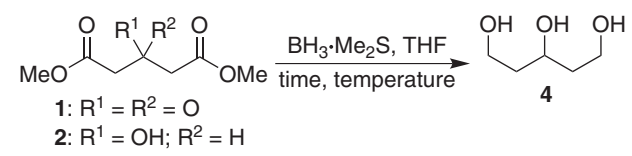

\begin{tabular}{lcccccc}
\hline Entry & Substrate & $\begin{array}{c}\mathrm{BH}_{3} \cdot \mathrm{Me}_{2} \mathrm{~S} / \\
\text { equiv. }\end{array}$ & $\begin{array}{c}\text { time } / \\
\mathrm{h}\end{array}$ & $\begin{array}{c}\text { Temperature / } \\
{ }^{\circ} \mathrm{C}\end{array}$ & $\mathbf{3}^{\mathrm{a} / \%}$ & $\mathbf{4}^{\mathrm{a} / \%}$ \\
\hline 1 & $\mathbf{1}$ & 3 & 24 & r.t. & 37 & 63 \\
2 & $\mathbf{2}$ & 3 & 24 & r.t. & 47 & 49 \\
3 & $\mathbf{1}$ & 2 & 24 & $45-50$ & 50 & 40 \\
4 & $\mathbf{2}$ & 2 & 24 & $45-50$ & 48 & 38 \\
5 & $\mathbf{1}$ & 3 & 48 & r.t. & 25 & 64 \\
6 & $\mathbf{1}$ & 4 & 24 & r.t. & 35 & 64 \\
7 & $\mathbf{1}$ & 3 & 24 & $45-50$ & - & 98 \\
\hline
\end{tabular}

a Isolated yield of analytically pure products.

\section{Conclusions}

In summary, we have reported efficient routes to 1,3,5-oxygenated pentanes with different oxidation states from the same precursor (dimethyl 3-oxopentanoate, $\mathbf{1}$ ). A chemoselective reduction to alcohol $\mathbf{2}$ was achieved in high yield (96\%) and was fully described, while diol $\mathbf{3}$ was obtained in $80 \%$ yield from $\mathbf{2}$, allowing a fast access to this important oxygenated synthon. Finally, a superior method of synthesis of triol 4 (98\% yield) was developed which employed a modified BMS reducing system.

\section{Experimental}

Reactions were performed using oven-dried glassware under an atmosphere of argon. Tetrahydrofuran was dried over sodium/benzophenone and freshly distilled before use. Methanol was distilled from methyl magnesium Grignard. Yields refer to chromatographically and spectroscopically pure compounds unless otherwise stated. All chromatography was carried out using slurry-packed Acros 0.060-0.200 mm silica gel. IR spectra were recorded on an ABB Bomen MB-Series GRAMS with internal referencing and selected absorption maxima $\left(v_{\max }\right)$ are reported in $\mathrm{cm}^{-1} .{ }^{1} \mathrm{H}$ NMR spectra were recorded on Varian Gemini 300 (300 MHz). Chemical shifts $(\delta)$ are quoted in ppm, to the nearest $0.01 \mathrm{ppm}$, and are referenced to the residual non-deuterated solvent peak. Coupling constants $(J)$ are reported in Hertz to the nearest $0.5 \mathrm{~Hz} .{ }^{13} \mathrm{C}$ NMR spectra were recorded on Varian Gemini $300(75 \mathrm{MHz})$. Chemical shifts $(\delta)$ are quoted in ppm, to the nearest $0.1 \mathrm{ppm}$, and are referenced to the residual non deuterated solvent peak.

\section{Synthesis of dimethyl 3-hydroxyglutarate (2)}

To a stirred solution of dimethyl 3-oxoglutarate (1008.1 mg, $5.79 \mathrm{mmol})$ in $\mathrm{MeOH}(15 \mathrm{~mL})$ at $0{ }^{\circ} \mathrm{C}$ was added portion wise $\mathrm{NaBH}_{4}(65.7 \mathrm{mg}, 1.74 \mathrm{mmol})$. The reaction was allowed to reach room temperature and after $24 \mathrm{~h}$ was quenched by addition of solid citric acid until $\mathrm{pH}$ reached 5 to 6 . To the reaction mixture was added silica gel $(c a .1 \mathrm{~g})$ and the solvent was distilled off. The residue was purified by column chromatography on silica gel (elution with AcOEt:hexane, 1:1) to afford the dimethyl 3-hydroxyglutarate $(977.2 \mathrm{mg}, 96 \%)$ as a colorless oil $\left(\mathrm{Rf}=0.3\right.$ with AcOEt:hexane 1:1 as eluent); IR $v_{\max } / \mathrm{cm}^{-1}$ : 3500, 1737, 1440, 1374, 1276, 1157 and 1045; ${ }^{1} \mathrm{H}$ NMR $\left(300 \mathrm{MHz} ; \mathrm{CDCl}_{3}\right) \delta 4.45$ (quint, $J 6.3 \mathrm{~Hz}, 1 \mathrm{H}$ ), 3.71 (s, 6H), $2.70(\mathrm{~b}, 1 \mathrm{H}), 2.55(\mathrm{~d}, J 6.3 \mathrm{~Hz}, 4 \mathrm{H}) ;{ }^{13} \mathrm{C} \mathrm{NMR}$ $\left(75 \mathrm{MHz} ; \mathrm{CDCl}_{3}\right) \delta 172.1,64.6,51.8,40.4$. Literature: ${ }^{5}$ IR $v_{\max } / \mathrm{cm}^{-1}: 3430$ and 1740; ${ }^{1} \mathrm{H}$ NMR $\left(\mathrm{CDCl}_{3}\right) \delta 4.48$ (quint, $J 6.2 \mathrm{~Hz}, 1 \mathrm{H}), 3.75(\mathrm{~s}, 6 \mathrm{H}), 3.63(\mathrm{~b}, 1 \mathrm{H}), 2.58$ (d, $J 6.0 \mathrm{~Hz}, 4 \mathrm{H})$.

\section{Synthesis of methyl 3,5-dihydroxypentanoate (3)}

To a stirred solution of dimethyl 3-hydroxyglutarate (200.1 mg, $1.14 \mathrm{mmol})$ in THF ( $3 \mathrm{~mL})$ under argon at room temperature was added $\mathrm{BH}_{3} \cdot \mathrm{Me}_{2} \mathrm{~S}$ (2 equiv., $216 \mu \mathrm{L}$, $2.28 \mathrm{mmol}$ ) drop to drop. After $48 \mathrm{~h}$ the reaction was diluted 
with $\mathrm{MeOH}(3 \mathrm{~mL})$ with intense formation of bubbles, and stirred for $1 \mathrm{~h}$. The solvent was distilled off and the residue purified by column chromatography on silica gel (elution with AcOEt:hexane 4:1 to $\mathrm{MeOH} / \mathrm{AcOEt}$ 1:19) to afford methyl 3,5-dihydroxy pentanoate $(135.9 \mathrm{mg}$, $80 \%)$ as a colorless oil $(\mathrm{Rf}=0.3$ with $\mathrm{AcOEt}$ as eluent). IR $v_{\max } / \mathrm{cm}^{-1}: 3452,1738,1435,1288,1171,1108,1011$; ${ }^{1} \mathrm{H}$ NMR (300 MHz; $\mathrm{CDCl}_{3}$ ) $\delta 4.23$ (quint, $J 6.3 \mathrm{~Hz}, 1 \mathrm{H}$ ), 3.97 (b, 1H), 3.77 (q, J 6.5 Hz, 2H), 3.67 (s, 3H), 2.90 (b, $1 \mathrm{H}), 2.48(\mathrm{~d}, J 6.2 \mathrm{~Hz}, 2 \mathrm{H}), 1.68(\mathrm{q}, J 6.0 \mathrm{~Hz}, 2 \mathrm{H}) ;{ }^{13} \mathrm{C} \mathrm{NMR}$ $\left(75 \mathrm{MHz} ; \mathrm{CDCl}_{3}\right) \delta$ 173.0, 67.2, 60.3, 51.8, 41.4, 37.8. Literature (Kingston et al. $\left.{ }^{2}\right):{ }^{1} \mathrm{H}$ NMR $\left(400 \mathrm{MHz}, \mathrm{CDCl}_{3}\right)$ $\delta 4.20(\mathrm{~m}, 1 \mathrm{H}), 3.90(\mathrm{br}, 1 \mathrm{H}), 3.75(\mathrm{~m}, 2 \mathrm{H}), 3.65(\mathrm{~s}, 3 \mathrm{H})$, $3.40(\mathrm{br}, 1 \mathrm{H}), 2.46(\mathrm{dd}, J 5.8$ and $1.2 \mathrm{~Hz}, 2 \mathrm{H}), 1.65(\mathrm{q}, J$ $5.6 \mathrm{~Hz}, 2 \mathrm{H}) ;{ }^{13} \mathrm{C}$ NMR $\left(100 \mathrm{MHz}, \mathrm{CDCl}_{3}\right) \delta$ 173.2, 67.4, $60.5,51.9,41.7,38.1$.

\section{Synthesis of 1,3,5-pentanetriol (4)}

To a stirred solution of dimethyl 3-oxoglutarate $(200 \mathrm{mg}$, $1.15 \mathrm{mmol})$ in THF $(3.5 \mathrm{~mL})$ under argon at $45-50{ }^{\circ} \mathrm{C}$ was added $\mathrm{BH}_{3} \cdot \mathrm{Me}_{2} \mathrm{~S}$ (3 equiv., $332 \mu \mathrm{L}, 3.45 \mathrm{mmol}$ ) drop to drop. After $48 \mathrm{~h}$ the reaction was diluted with $\mathrm{MeOH}$ (3.5 $\mathrm{mL}$ ) with intense formation of bubbles, and stirred for $1 \mathrm{~h}$. The solvent was distilled off and the residue purified by column chromatography on silica gel (elution with AcOEt to MeOH:AcOEt 1:9) to provide 1,3,5-pentanetriol $(135.2 \mathrm{mg}, 98 \%)$ as a viscous oil $(\mathrm{Rf}=0.1$ with $\mathrm{AcOEt}$ as eluent). IR $v_{\text {max }} / \mathrm{cm}^{-1}: 3348,2944,2888,1422$, 1062; ${ }^{1} \mathrm{H}$ NMR (300 MHz; $\left.\mathrm{CD}_{3} \mathrm{COCD}_{3}\right) \delta 4.05-3.92(\mathrm{~m}$, $2 \mathrm{H}), 3.80-3.65(\mathrm{~m}, 4 \mathrm{H}), 2.98(\mathrm{~m}, 2 \mathrm{H}), 1.70-1.50(\mathrm{~m}, 4 \mathrm{H})$; ${ }^{13} \mathrm{C}$ NMR $\left(75 \mathrm{MHz} ; \mathrm{CD}_{3} \mathrm{COCD}_{3}\right) \delta \quad 69.2,60.5,40.7$. Literature (Wender et al. at reference 2): IR $v_{\max } / \mathrm{cm}^{-1}$ : 3338, 2944, 2888, 1421, 1061; ${ }^{1} \mathrm{H}$ NMR (500 MHz; $\left.\mathrm{D}_{2} \mathrm{O}\right)$ $\delta 3.82(\mathrm{~m}, J 4.0 \mathrm{~Hz}, 1 \mathrm{H}), 3.64$ (s, J $6.5 \mathrm{~Hz}, 4 \mathrm{H}), 1.66$ (m, $4 \mathrm{H}) ;{ }^{13} \mathrm{C}$ NMR (125 MHz; CD OD) $\delta 67.4,60.1,41.1$.

\section{Acknowledgments}

Financial support from Centro Universitário FIB (fellowship to V. B. C.) is gratefully acknowledged. We thank Dr. S. D. Cunha, Dr. J. M. David and Dr. R. A. Pilli for support.

\section{References}

1. Seyden-Penne, J. In Reductions by the Alumino and Borohydrides in Organic Synthesis; Curran, D. P. ed.; $2^{\text {nd }}$ ed.; Wiley-VCH: New York, 1997; Hudlikly, M. In Reductions in Organic Chemistry; $2^{\text {nd }}$ ed.; John Wiley \& Sons: New York, 1984.
2. For examples of syntheses employing 2, see: Mitton-Fry, M. J.; Cullen A. J.; Sammakia, T.; Angew. Chem., Int. Ed. 2007, 46, 1066; McAllister, L. A.; Hixon, M. S.; Schwartz, R.; Kubitz, D. S.; Janda, K. D.; Bioconjugate Chem. 2007, 18, 559. Employing 3, see: Chen, K. H.; Ganesh, T.; Brodie, P.; Slebodnick, C.; Jiang, Y.; Banerjee, A.; Bane, S.; Snyder, J. P.; Kingston, D. G. I.; Org. Biomol. Chem. 2008, 6, 4542. Employing 4, see: Sax, M.; Fröhlich, R.; Schepmann, D.; Wünsch, B.; Eur. J. Org. Chem. 2008, 6015; Hollenstein M.; Leumann, C. J.; Org. Lett. 2003, 5, 1987; Wender, P. A.; Baryza, J. L.; Bennett, C. E.; Bi, F. C.; Brenner, S. E.; Clarke, M. O.; Horan, J. C.; Kan, C.; Lacôte, E.; Lippa, B.; Nell, P. G.; Turner, T. M.; J. Am. Chem. Soc. 2002, 124, 13648.

3. Dimethyl 3-oxoglutarate: U\$ 30.00/25g or U\$ 82.80/100g; dimethyl 3-hydroxyglutarate: U\$222.00/25g. Source: Aldrich Chemistry Catalog 2009-2010.

4. Cappuyns, L.; Bull. Soc. Chim. Bel. 1945, 54, 73; Lochte, H. L.; Pickard, P. L.; J. Am. Chem. Soc. 1946, 68, 721; Paul, R.; Tchelitcheff, S.; Bull. Soc. Chim. Fr. 1951, 18, 550; Grundmann C.; Paul, H.; Chem. Ber. 1953, 86, 186; Stetter, H.; Bander, O. E.; Neumann, W.; Chem. Ber. 1956, 89, 1922.

5. Lam, L. K. P.; Jones, J. B.; Can. J. Chem. 1988, 66, 1422. A good yield but tedious aqueous procedure is also described: Roy, R.; Rey, A. W.; Synlett 1990, 448; Cohen, S. G.; Khedouri, E.; J. Am. Chem. Soc. 1961, 83, 4228.

6. Mori, K.; Ikunaka, M.; Tetrahedron 1987, 43, 45.

7. Acevedo, C. M.; Kogut, E. F.; Lipton, M. A.; Tetrahedron 2001, 57, 6353.

8. Saito, S.; Hasegawa, T.; Inaba, M.; Nishida, R.; Fujii, T.; Nomizu, S.; Moriwake, T.; Chem. Lett. 1984, 1389.

9. Thiam, M.; Slassi, A.; Chastrette, F.; Amouroux, R.; Synth. Commun. 1992, 22, 83. See also Kingston et al. ${ }^{2}$.

10. Loubinoux, B.; Sinnes, J. L.; O’Sullivan, A. C.; Winkler, T.; Tetrahedron 1995, 51, 3549.

11. Prepared by treatment of anion of ethyl acetoacetate with benzyl chloromethyl ether: Taylor, E. C.; LaMattina, J. L.; J. Org. Chem. 1978, 43, 1200.

12. Miyashita, M.; Suzuki, T.; Hoshino, M.; Yoshikoshi, A.; Tetrahedron 1997, 53, 12469.

13. Brown, H. C.; Krishnamurthy, S.; Tetrahedron 1979, 35, 567. 14. Adkins, H.; Billica, H. R.; J. Am. Chem. Soc. 1948, 70, 3121.

15. Viscontini, M.; Ebnother, C.; Helv. Chim. Acta 1951, 34, 116; Jacobs, M. F.; Suthers, B. D.; Hübener A.; Kitching, W.; J. Chem. Soc., Perkin Trans. I 1995, 901. A non-direct four steps synthesis is described in high yields, but without experimental details. See reference 6 .

16. Reagent is 1,6-heptadien-4-ol: U\$ 356.00/25g. See Wender et al. ${ }^{2}$.

Submitted: May 25, 2010 Published online: July 29, 2010 